\title{
Por uma didática clínica: a formação do professor de psicologia
}

\author{
Tânia Maria Baibich \\ Universidade Federal do Paraná
}

\begin{abstract}
Resumo
Este estudo trata da natureza e da qualidade da formação do professor de psicologia com a finalidade de subsidiar as mudanças na estrutura curricular do curso de Licenciatura em Psicologia, tendo como base uma pesquisa aplicada junto aos alunos formandos na qual se procurou investigar os atributos de um Bom Professor. Analisando os resultados da pesquisa e partindo da concepção de que a reflexão coletiva e permanente sobre o processo de ensino-aprendizagem permite aprimorar a vinculação do método didático ao método de pensamento, na medida em que desvela para os próprios atores do processo a epistemologia que subjaz a toda e qualquer ação educativa, este estudo conclui pela necessidade de uma "didática clínica" para a formação do Bom Professor de Psicologia.
\end{abstract}

Palavras-chave: licenciatura em Psicologia; didática clínica; princípios do ensino de Psicologia.

\begin{abstract}
Towards a clinical pedagogy: the development of the psycology teacher

This study deals with the nature and the quality of development of a teacher's psychology with the purpose of subsidizing modifications to the curriculum structure of the Psychology Teacher Graduation Course. The study was based on a research applied to graduating students and tries to highlight the attributes of a "Good Teacher". Analyzing the research's results and considering collective and permanent reflections on the teaching/learning process allows one to improve the connection of didactic to thought method. In the way that it discloses process actors, the epistemology underlies any educational action, this study concludes the necessity of a "didactical clinic" for the Psychology's Good Teacher formation.

Keywords: Psychology, bed degree; clinical Pedagogy; teaching of Psychology.
\end{abstract}

O objetivo deste estudo é analisar a natureza e a qualidade da formação do professor de psicologia, tendo como suporte empírico a avaliação dos alunos formandos, com a finalidade de fundamentar uma reflexão acerca das mudanças mais necessárias no âmbito curricular, propriamente dito, e no "currículo vivo", que é o espaço da sala de aula. Para tanto, tomou-se como referência as novas formulações da Lei de Diretrizes e Bases, especificamente no que se refere aos cursos de Licenciatura em Psicologia. Para melhor localizar o âmbito em que este estudo se desenvolve, convém indicar que o curso de Licenciatura em Psicologia referido deve ser oferecido em uma Instituição Federal de Ensino Superior - IFES, estando, o novo currículo, em fase de discussão, tendo em vista que os novos currículos de Bacharelado e o de Formação de Psicólogo já foram aprovados em 2001.

Para alcançar o objetivo explicitado, procurou-se fazer uma análise dos suportes teórico-práticos para a formulação da proposta de um curso de Licenciatura, o qual possa habilitar os futuros professores de psicologia a traduzirem conteúdos e métodos do ensino desta disciplina, no sentido de torná-la acessível e significativa para os alunos dos Ensinos Fundamental e Médio. A partir da reflexão acerca das ações docentes que constituem este curso de formação de professores, buscou-se alcançar um objetivo complementar que é destacar algumas pedras angulares do ensino de psicologia.

Partindo dos conhecimentos acumulados, expostos na literatura, relativos ao desenvolvimento afetivo e cognitivo que a psicologia construiu ao longo de sua história e, muito especialmente, de sua ausência ou de sua presença gauche $e^{1}$ na sala de aula do Ensino Fundamental e do Ensino Médio, torna-se necessário incentivar a construção de alternativas metodológicas que contribuam para a transformação do status que este conhecimento ainda hoje ocupa na escola. Dito de outra maneira, reflexões teórico-metodológicas acerca do método didático mais adequado para que os conteúdos da psicologia possam, efetivamente, se fazer presentes na educação de crianças e adolescentes, no âmbito da Escola, são atuais e urgentes.

É com este sentido que o presente estudo pretende discutir, a partir da avaliação dos alunos formandos na 
Licenciatura em Psicologia, os sentidos da formação do professor, a qual deve considerar o

exercício da descoberta e análise da projeção que ele como sujeito faz de um BOM PROFESSOR. Se a pesquisa mostrou a tendência de reprodução da ação docente, é necessário pelo menos que o professor tenha clara e organizadamente esta idéia de dever-ser em mente (Cunha, 1989, p. 169).

Esta análise tem por princípio a concepção de que a reflexão coletiva e permanente sobre o processo de ensino-aprendizagem permite aprimorar a vinculação do método didático ao método de pensamento, na medida em que desvela para os próprios atores do processo a epistemologia que subjaz a toda e qualquer ação educativa.

\section{Breves Notas Metodológicas}

Cabe aqui uma breve consideração sobre $\mathrm{o}$ significado, tanto para alunos quanto para professores e aspirantes a professores, acerca da reflexão sobre a ação própria, sobre os sentimentos, pensando a teoria para lidar com os desafios da prática. A condição de albergar o não-saber parece ser condição básica para o desenvolvimento de qualquer projeto pedagógico que se pretenda educativo. $\mathrm{O}$ albergue para a falta, antes de significar uma atitude passiva de conformidade, constitui-se como possibilidade de aceitar o desafio, tolerar a dor e a frustração, criando novos espaços internos para novos saberes.

Do ponto de vista metodológico, este estudo considera que

tanto o pesquisador quanto o objeto pesquisado estão em movimento e, portanto, em uma condição em que ambos se constroem durante a trajetória da investigação. A percepção do sujeito pesquisador e sua condição de interpretação do real move-se à medida que investiga; ao mesmo tempo, move-se o real, que não apenas fornece ao investigador novos elementos como revela a essência dialética dos seus elementos constitutivos: sujeito e objeto não se constituem em uma unidade, mas interagem dinâmica e contraditoriamente. A realidade, seja a histórica, seja a distante, independe do sujeito pesquisador específico, mas não é externa a ele, ainda que com ele não se venha a confundir. Se o sujeito e o objeto fossem uma unidade, uma única e mesma coisa, tanto o sujeito seria redutivel ao objeto como este ao sujeito e, assim, toda a realidade seria plenamente cognoscivel em quaisquer circunstâncias. A realidade existe conscientemente para o sujeito pesquisador quando o mesmo interage com ela e esta interação se dá por um processo no qual o pesquisador percebe o real segundo um esquema de assimilação e acomodação que lhe é próprio, construído ao longo de seu desenvolvimento cognitivo $e$ de suas relações sociais. Ao mesmo tempo em que se dá esta percepção, desencadeia-se uma re-elaboração da leitura do real, pois quanto mais se aprofunda a interação dialética sujeito-objeto, mais este é dado a conhecer àquele, de forma que o sujeito pode cada vez mais dominar o objeto, mesmo sabendo que este domínio esteja indicando o quanto o objeto é ainda desconhecido para o sujeito (Faria, 2003, p. 9).

Neste sentido, para fins de análise, foram utilizadas avaliações de 17 alunos relativamente à Licenciatura em Psicologia ainda na vigência do currículo anterior, a partir de suas experiências vividas, nas quais foi possível elaborar e reelaborar a compreensão sobre o processo ensino-aprendizagem. Ressalte-se que estes alunos tiveram um mesmo professor como responsável pelas disciplinas específicas, quais sejam, Metodologia e Prática de Ensino de Psicologia, fato este que contribuiu sobremaneira para a interação sujeito-objeto.

Para efeitos de aproximação do estudo com a realidade a ser estudada, ao final da disciplina de Metodologia do Ensino de Psicologia ${ }^{2}$, foi realizada uma avaliação qualitativa pelos alunos, a qual sugeriu resultados positivos da aprendizagem, sendo que a grande parte das observações centrava-se na atuação docente, considerando tanto os aspectos relativos a conteúdo, quanto aos de metodologia, da relação professor-alunos, da postura ética e política do professor e de suas consequiências benéficas para a aprendizagem. Alguns trechos selecionados desta avaliação são bastante ilustrativos:

\begin{abstract}
"Considero estas aulas um presente, pois o domínio que a professora tem da matéria $e$ o profissionalismo que demonstra é excepcional."

“...aulas muito gostosas, numa turma excelente para trabalhar e com uma professora ótima como pessoa e com excelentes conhecimentos teóricos, práticos e com extrema ética."
\end{abstract}

“...é uma pessoa que segue o que prega;[...] a prática e a teoria não são uma contradição.”

"a professora tem uma disponibilidade incrível para responder às questões dos alunos e incentivá-los. Critica muito bem."

"excelente o equilíbrio entre limite $x$ liberdade/criatividade do aluno, na medida em que os conteúdos foram criteriosamente delimitados [...] propiciou que o seu desenvolvimento respeitasse não só a dinâmica da disciplina como também a dinâmica do próprio aluno."

"Senti, durante o curso da disciplina, ampla motivação e conhecimento da parte da professora, o que acabou despertando o interesse e empenho da turma."

“...admiro sua bagagem intelectual e gostei muito de participar das tuas aulas. [...] tua forma de trabalhar o conteúdo motiva a participação constante e a curiosidade e reciprocidade entre os colegas."

Estas primeiras avaliações, ainda de caráter semiestruturado, serviram de base para as definições de quais questões deveriam merecer uma análise mais detalhada sobre a relação ensino-aprendizagem na formação de professores na Licenciatura de Psicologia. Pode-se observar, a partir destes trechos, 
as seguintes questões: (i) domínio teórico e prático da disciplina; (ii) ética e profissionalismo; (iii) não cisão entre teoria e prática; (iv) limites entre crítica, liberdade e criatividade; (v) motivação. As respostas permitiram uma leitura no sentido da reflexão teórica acerca da formação destes professores no intuito não apenas de subsidiar a elaboração de um novo currículo mas, muito especialmente, na intenção da construção de uma "didática clínica".

As primeiras avaliações induziram a discussão de quatro importantes categorias, que serão analisadas em detalhe na sequiência: (i) motivação para a licenciatura e concepção de bom professor; (ii) significado dos cursos de licenciatura e da formação de psicólogo na formação do bom professor de psicologia; (iii) a prática do professor que ensina e a prática do professor que não ensina; (iv) alterações curriculares. Para a análise destas categorias, foi elaborado um questionário estruturado, aberto, o qual foi aplicado junto a 17 alunos, que participaram da primeira avaliação, cujas respostas permitiram as análises que seguem. Estes alunos haviam cursado a disciplina de Prática de Ensino de Psicologia e, quase em sua totalidade, haviam cursado igualmente Metodologia de Ensino de Psicologia com o mesmo professor. A cada aluno que participou da pesquisa foram apresentadas as questões decorrentes da primeira avaliação semi-estruturada. Sendo o questionário aberto, cada aluno avaliou e indicou atributos ou características que julgava mais importantes, de maneira que as medidas realizadas referem-se não ao número de respondentes, mas ao número de respostas ou menções. Cada entrevistado poderia comentar suas respostas, permitindo com isto qualificar as análises.

\section{Licenciatura: da escolha e da habilitação}

Ainda que cada aluno pudesse indicar mais de um motivo para a escolha da Licenciatura, confirmando análises anteriores de outras turmas, a maioria dos alunos que respondeu ao questionário opta por esta formação pois vê a possibilidade de abertura de campos de atuação profissional, tenham eles ou não afinidade prévia com o ensinar. Este dado reforça o diagnóstico já familiar para professores da área de que, na Psicologia, a Licenciatura, pelo menos de um princípio, é tida como opção menos nobre, que demandaria menor esforço e comprometimento do aluno e menos competência e exigência dos professores.

No decurso do estágio de Prática de Ensino de Psicologia - PEP, a percepção das dificuldades para obtenção de trabalho manifesta-se com mais força quando da avaliação quanto à suficiência da habilitação em Licenciatura para o trabalhar como professor. Dos alunos que entendem que a Licenciatura os formou parcialmente, há muitas justificativas ligadas mais a questões do mercado de trabalho do que ao curso propriamente dito. Assim, dos entrevistados, $29 \%$ consideram que a habilitação foi total, e $71 \%$, que foi parcial, sendo que, na maioria dos "parciais", o motivo alegado relacionava-se à nãosuficiência do curso para uma automática abertura de portas no mercado de trabalho em geral ou no campo da docência superior, em particular: "contribuiu para minha formação mas não possibilitou aberturas no mercado de trabalho"; "não atendeu minha pretensão de docência universitária para a qual esta titulação não é obrigatória e demanda Especialização ou Mestrado".

Entre os alunos que não se vêem como totalmente habilitados, há os que apontam falhas no desempenho de alguns professores da mesma forma em que os que se sentiram totalmente habilitados mencionam o desempenho do professor de Metodologia do Ensino da Psicologia - MEP - e de PEP como responsável pela sua habilitação. É possível constatar, portanto, que na avaliação do aluno, em geral, é do professor a responsabilidade quase que total da sua formação, aspecto também geralmente corroborado pela herança tradicional do sistema de ensino.

Ainda considerando que este problema de campo de trabalho se evidencie como importante, é possível observar que tanto a Licenciatura quanto o curso de Formação de Psicólogo são avaliados como tendo sido formadores do "bom professor de psicologia", sendo que o de Formação de Psicólogo aparece como fornecedor de conhecimentos específicos da psicologia tidos como pré-requisitos para a função. 59\% dos alunos consideram que o curso de Formação de Psicólogo teve muita contribuição para sua formação como licenciados em psicologia, e as razões para tanto ligam-se, mais notadamente, a conteúdos específicos que as diferentes disciplinas proporcionaram aprender: "aprimora o olhar sobre alunos e aprendizagem"; "aperfeiçoa o feeling"; "fornece conhecimentos sobre dinâmica de grupo, desenvolvimento infantil, adolescência, instituição 
escola"; "riqueza das disciplinas ligadas à prática escolar"; "diversidade de conteúdos e visões dos professores".

No entanto, dos $35 \%$ de alunos que consideraram razoável a contribuição do curso de Formação de Psicólogo e de um que considerou a contribuição quase nula, as causas são também relacionadas a currículo, professores e disciplinas, mas pelo lado reverso: "muitas disciplinas falhas"; "auxilia para o domínio de conteúdo mas não para noções de como trabalhá-lo"; "não trata de questões específicas do ensinar"; "quase nenhuma ligação com a educação e falta de professores em disciplinas como Psicologia de Aprendizagem".

\section{O Bom Professor de Psicologia}

Fica claro, desta forma, que os alunos têm a concepção da necessidade de que as habilitações devem constituir suporte uma às outras e é desta efetivação ou das suas falhas que advém a possibilidade de a Licenciatura conferir apenas Habilitação ou, também, habilidades. Fica evidenciado o papel do "bom professor de psicologia"para a formação dos futuros professores, dada a tendência de reprodução já comprovada em estudos anteriores (Cunha, 1989).

É tão explorada na literatura, quanto é de conhecimento de quem trabalha com formação de professores, a força do exemplo de ex-professores sobre o comportamento docente. Deste modo faz-se imprescindível refletir sobre a imagem de "bom professor de psicologia" destes alunos, em grande parte formandos ou formados em Psicologia e, portanto, com experiência como alunos e já com alguma experiência da prática de ensino.

A Tabela 1 mostra este questionamento e também relaciona o quanto os alunos aquilataram que sua formação tenha sido significativa para formar-lhes enquanto "bons professores"ou não. As respostas indicam que domínio de conteúdo e que conhecimento de didática e de metodologia constituem-se nos dois principais requisitos para a formação do bom professor. É interessante notar que, enquanto o conhecimento didático e metodológico é proporcionado de forma significativa pela Licenciatura, o domínio de conteúdo é proporcionado principalmente mas não significativamente pelo Curso de Formação de Psicólogo, ressaltando o papel da Licenciatura neste particular.

Tabela 1 - Requisitos para "Ensinar bem Psicologia"

\begin{tabular}{|c|c|c|c|}
\hline \multirow[t]{2}{*}{ Requisitos Mencionados } & \multirow{2}{*}{$\begin{array}{c}\text { Freqüêencia das } \\
\text { Respostas (\%) }\end{array}$} & \multicolumn{2}{|c|}{ Contribuição Para o Desenvolvimento dos Requisitos } \\
\hline & & Curso de Formação de Psicólogo (\%) & Licenciatura $(\%)$ \\
\hline Conhecimento & & & \\
\hline $\begin{array}{lll}\text { Didática } & \text { e } & \text { de } \\
\text { Metodologia } & & \end{array}$ & 19,7 & 16,7 & 83,3 \\
\hline Domínio de Conteúdo & 15,8 & 53,8 & 46,2 \\
\hline Conhecimento & & & \\
\hline $\begin{array}{ll}\text { Processos } & \text { de } \\
\text { Aprendizagem } & \end{array}$ & 5,3 & 60,0 & 40,0 \\
\hline Amor & 5,3 & 50,0 & 50,0 \\
\hline $\begin{array}{l}\text { Dedicação, } \\
\text { Responsabilidade, } \\
\text { Comprometimento }\end{array}$ & 5,3 & 50,0 & 50,0 \\
\hline $\begin{array}{l}\text { Manejo da Turma, } \\
\text { Conhecimento } \\
\text { Dinâmica de Grupo }\end{array}$ & 5,3 & 50,0 & 50,0 \\
\hline $\begin{array}{l}\text { Compreensão do } \\
\text { Indivíduo, Experiência } \\
\text { Clínica, Ser Bom Ouvinte }\end{array}$ & 5,3 & 66,7 & 33,3 \\
\hline $\begin{array}{l}\text { Discernimento de Papéis } \\
\text { de Professor e Psicólogo }\end{array}$ & 5,3 & 33,3 & 66,7 \\
\hline Outros Requisitos & 32,7 & 39,0 & 41,0 \\
\hline Total & 100 & $42,0 *$ & $58,0 *$ \\
\hline
\end{tabular}

* Média das respostas considerados os valores absolutos.

Percebe-se, pelas demais respostas, uma vinculação entre domínio de conteúdo e forma de ensiná-lo. No conjunto dos outros requisitos é oportuno destacar as seguintes menções: (i) habilidades de comunicação; (ii) boa relação interpessoal; (iii) experiência; (iv) postura ética; (v) conhecimento de políticas e estruturas da educação; (vi) humildade; (vii) ambição; (viii) flexibilidade; (ix) referencial bibliográfico; (x) mestrado; (xi) pensamento que promova sínteses e reflexões; (xii) desenvoltura; (xiii) apresentação; (xiv) cuidado para não generalizar informações; (xv) capacidade de favorecer o desenvolvimento dos alunos.

Para a melhor leitura destas respostas é necessário indicar que as respostas tanto referem-se a atributos de caráter individual como aos de caráter de formação. 
Neste último caso, pode-se classificar estes atributos em quatro extratos: formação/conteúdo; formação/metodologia; formação/ética e formação/política. Procedendo desta maneira, é possível avaliar as respostas e as respectivas influências da Licenciatura e/ou do curso de Formação de Psicólogo na formação do bom professor, conforme se encontra na Tabela 2.

Convém, a este respeito, observar que

$a$ as características individuais, mesmo considerando as influências sofridas no decurso da formação do professor de psicologia, têm um peso maior do que as de conteúdo e de ética, o que, de certa forma, sublinha o caráter de dom que ainda possui a profissão na representação dos alunos;

$b$ as características relativas a conhecimento e postura política são tidas como muito pouco expressivas face às de metodologia, de características individuais, de conteúdo e de ética, nesta mesma ordem de importância. Este dado, vinculado ao anterior, reforça a idéia de profissão pouco comprometida com a situação e os rumos do país e do mundo. Parece ser bastante o ideal e o método, como se os anos 50, 60 e 70 ainda vigorassem no imaginário dos futuros professores de psicologia. Da mesma forma o caráter individual da psicologia dissociado do sociopolítico ainda parece ser o principal paradigma de compreensão da realidade;

c. as características relativas à metodologia assumem o valor máximo para a ação docente o que, além de corroborar as análises feitas acima, parece retirar do sujeito aprendiz a força de seu papel na relação de ensinoaprendizagem, deixando ao mestre a função de fazer a aprendizagem acontecer;

d. tanto o curso de formação de psicólogo quanto a Licenciatura são tidos como básicos para a formação do "bom professor de psicologia", ainda que as características de caráter individual sejam significativamente consideradas enquanto suporte para a ação deste professor;

e. existe uma percepção clara de que o "bom professor de psicologia", além dos conhecimentos acerca do desenvolvimento cognitivo, necessita do conhecimento do desenvolvimento afetivo, não para utilizá-los como psicólogo clínico ou escolar mas para melhor ensinar os conteúdos desta disciplina que pede, incessantemente, a integração destes saberes.

Tabela 2 - Influências na Formação do Professor.

\begin{tabular}{l|ccc}
\hline Caráter & $\begin{array}{c}\text { Freqüência das Respostas } \\
(\%)\end{array}$ & $\begin{array}{c}\text { Influência Curso de } \\
\text { Formação de Psicólogo (\%) }\end{array}$ & $\begin{array}{c}\text { Influência Curso de } \\
\text { Licenciatura (\%) }\end{array}$ \\
\hline Individual & 21,8 & 50,0 & 50,0 \\
Formação/conteúdo & 15,4 & 53,8 & 42,6 \\
Formação/metodologia & 43,6 & 17,4 & 82,6 \\
Formação/ética & 15,4 & 41,7 & 58,3 \\
Formação/política & 3,8 & 0 & 100,0 \\
Total & 100 & $35,4^{*}$ & $64,6^{*}$ \\
\hline
\end{tabular}

*Média das respostas considerados os valores absolutos.

\section{A prática do Ensino de Psicologia do professor que ensina e a do que não ensina}

Dada a importância que tem a atuação do professor na formação do aluno e, muito especialmente, daquele que forma o formador, cabe olhar mais acuradamente este movimento da ação docente, na perspectiva do sujeito aprendiz. Com este objetivo, foram formuladas questões no intuito de verificar quais as disciplinas da Licenciatura que foram consideradas como as que mais formaram para a função e quais aquelas que pouco ou nada contribuíram para a formação do futuro professor de psicologia.

As respostas, constantes da Tabela 3, indicam que todos os alunos consideraram que PEP e/ou MEP foram as grandes responsáveis pela formação. Dentre os prováveis fatores para tal escolha, é possível considerar as características do professor e/ou o fato de serem ambas disciplinas com especificidade de conteúdos de psicologia, além das referências às condições integradas de conhecimento do conteúdo, da metodologia de ensino e da postura ético-afetiva.
Observa-se, aqui, de certa forma, também uma unanimidade no julgamento do que pouco ou nada contribuiu para a formação: as disciplinas de Estrutura e Funcionamento do Ensino de I e II Graus e Didática são as únicas referidas neste status. Ressalte-se, como reforço ao argumento já exposto, que nenhuma das duas disciplinas trata de conteúdos específicos da psicologia ou é ministrada por professor que seja também psicólogo, o que pode ter interferido na avaliação dos alunos, já que nenhum deles justificou a escolha destas opções ${ }^{4}$.

Com relação ao conteúdo trabalhado, os alunos ressaltam a amplitude, a profundidade, a permanente relação teoria e prática e a incitação ao pensamento original, quando se referem ao Bom Professor. Já, ao tratarem do mesmo aspecto quanto às disciplinas que pouco formaram, percebem um conteúdo confuso, vago, com textos aleatórios que não permitiram captar o objetivo da disciplina ou, ainda, a leitura em sala de aula, durante o semestre inteiro, da Lei de Diretrizes e Bases. No que tange às bibliografias utilizadas, enquanto a do Bom Professor foi considerada atualizada, completa, interessante e direcionada ao 
tema, a das disciplinas que pouco ou nada contribuíram para a formação foi considerada "extensa", "sem nexo","sem articulação com a prática", a ponto inclusive de vários alunos sequer lembrarem da mesma.

Tabela 3 - Contribuições das Disciplinas para a Formação

\begin{tabular}{lcc}
\hline Disciplina & Mais contribuiu (\%) & Menos contribuiu (\%) \\
\hline Didática & 0 & 15,4 \\
Estrutura e Funcionamento do Ensino de I e II Graus & 0 & 69,2 \\
Metodologia do Ensino de Psicologia & 13,2 & 0 \\
Prática de Ensino de Psicologia & 21,7 & 0 \\
Metodologia e Prática & 26,1 & 0 \\
Estrutura e Prática & 4,3 & 0 \\
Estrutura, Metodologia e Prática & 4,3 & 0 \\
Didática e Prática & 8,7 & 0 \\
Estrutura e Didática & 0 & 15,4 \\
Todas & 21,7 & 0 \\
Total & 100 & 100 \\
\hline
\end{tabular}

Nas referências ao papel da metodologia de ensino do professor, o Bom Professor, além de exercer um constante exercício crítico consigo mesmo ${ }^{5}$, fez com que as aulas transcorressem em um ambiente muito tranqüilo, instigante e de cooperação. A maneira pela qual as críticas eram feitas pelo professor foram, no entendimento dos alunos, de vital importância no desenvolvimento de habilidades, ainda que permitindo sempre a expressão dos alunos, respeitando-os e fazendo-os ir em busca do conhecimento. O professor, neste caso, reúne características como conteúdo, didática, dedicação, "humildade e amor", conservando sempre, com muito cuidado, todo o debate teórico e articulando a metodologia com os objetivos. Contrariamente, no caso oposto, as referências foram relativas à confusão, desorganização, repetição de técnicas que tornavam a disciplina extremamente cansativa.

A relação professor-alunos constitui um aspecto bastante interessante para a análise, na medida em que permite qualificar o Bom Professor como aberto ao diálogo e ao esclarecimento, verdadeiro, crítico, instigador, motivador, generoso, respeitoso e dirigido ao aprendizado. Ao mesmo tempo, tal relação permite reconhecer nas disciplinas que pouco formaram, um "clima muitas vezes favorável", ainda que sem envolvimento. Isto sugere que o bom relacionamento por si só não constitui condição suficiente para a aprendizagem, ainda que necessário.

Da mesma forma, quando a análise recai sobre o grau de conhecimento do professor, o que se vê não é, necessariamente, um contraponto entre o Bom e o Mau Professor. O Bom é visto como aquele que demonstra grande acúmulo de conhecimento, tanto de conteúdo, de métodos, de políticas da educação, como tem uma atitude de "pesquisador-aprendiz", constituindo-se num "modelo". Já o professor da disciplina que, de acordo com os alunos, pouco formou, nem sempre foi visto como alguém sem o domínio do conteúdo, ou com pouca condição de articulação com a prática; por alguns alunos foi caracterizado como "bom, mas sem clareza de propósito"ou, até mesmo "muito bom ou ótimo, contudo sem trabalhar com conexão com a licenciatura de psicologia". Neste quesito, como no anterior, há a noção de necessidade, porém não a de suficiência para que a aprendizagem se efetive.

Quanto à significância dos conteúdos trabalhados para a futura formação de professor de psicologia, os do Bom Professor auxiliaram na construção de concepções teóricas, políticas e metodológicas, contribuindo grandemente para a formação, e "não apenas para formação como professor"; já no caso das disciplinas que menos contribuíram, o conteúdo trabalhado foi percebido como tendo pouquíssima significância com a formação do futuro professor de psicologia. É preciso ressaltar que alguns alunos, da mesma forma como nos quesitos da relação professoralunos e no de conhecimento do professor, reconhecem que ainda que os "conteúdos fossem bons, a forma de trabalhá-los deixou a desejar"ou que "acrescentaram para o desenvolvimento do pensamento crítico mas pouco com relação ao ensino de psicologia"

O processo de avaliação utilizado pelo Bom Professor, tido como efetivamente avaliador, foi caracterizado como processual, rico, possibilitando o amadurecimento e a troca de experiências. No caso das disciplinas que menos contribuíram, foi definido como pobre, reduzido à utilização de questionários ou de um trabalho escrito que pouco acrescentou à formação. Quando a avaliação se dava por trabalhos em grupo, "devido ao pouco interesse dos alunos pela disciplina, [as tarefas] acabavam sendo divididas em partes, sem que todos tivessem a noção do todo".

Confirmando pesquisa anterior acerca da avaliação dos alunos com respeito ao Bom Professor e sua prática pedagógica (Cunha, 1989), os alunos formandos do curso de Licenciatura em Psicologia afirmam que a aprendizagem está relacionada a vários aspectos: (i) autoridade do professor devido ao seu saber (que, pelo menos no início do processo, supera o do aluno); (ii) método de trabalho que contenha, no mesmo espaço, a crítica, o prazer, o diálogo, a atitude de pesquisador-aprendiz, a postura cooperativa no sentido da formação de sujeitos moral e 
intelectualmente autônomos, sujeitos epistêmicos; (iii) a postura de planejamento e avaliação claros, flexíveis - ainda que firmes - e eficientes; (iv) a significância dos conteúdos para os objetivos aos quais a disciplina se propõe, bem como a relação permanentemente estabelecida entre teoria e prática, entre outros.

O conjunto de características necessárias para que a aprendizagem, função precípua da Escola, aconteça, parece ser uma quase unanimidade. Assim, o fato de o professor ser conhecedor de sua matéria ou de relacionar-se bem com os alunos não é suficiente para que a aprendizagem se efetive, haja vista as considerações positivas sobre o conhecimento do conteúdo ou a relação com os alunos dos professores das disciplinas que menos contribuíram para a formação do aluno. O método didático percebido como aquele que alcança aquilo a que se propõe é o resultado de uma composição técnica, política (esta dificilmente percebida em nível consciente) e afetiva, que ensina para mais além de sua ementa, pois ensina atitudes para aprender.

Reforçando o fato de que a avaliação dos alunos é, em geral, pertinente e adequada, as sugestões para mudança, em sua maioria, devem constituir o novo currículo que se encontra em estudo. Além da ampliação do número de horas da licenciatura, deve haver um aumento substantivo da Prática de Ensino e a inclusão de disciplina de natureza prática sobre aprendizagem, ministrada pelo Departamento de Psicologia.

Tabela 4 - Propostas de Mudanças Curriculares.

\begin{tabular}{l|cc}
\hline Mudanças curriculares/Natureza & Sim (\%) & Não (\%) \\
\hline Alteração de carga horária* & 19,6 & 30,0 \\
Alteração de carga horária da Prática de Ensino* & 21,4 & 25,0 \\
Exclusão de Disciplina & 1,8 & 0 \\
Inclusão de Disciplina & 12,5 & 0 \\
Substituição de Professor & 10,7 & 45,0 \\
Inclusão de disciplina no Bacharelado & 16,1 & 0 \\
Ampliação de conteúdos e atividades & 7,1 & 0 \\
Redução de conteúdos & 3,6 & 0 \\
Exclusão de disciplina & 3,6 & 0 \\
Outras & 3,6 & 0 \\
Total & 100 & 100 \\
\hline
\end{tabular}

* As alterações, sem exceção, referem-se ao aumento da carga horária.

Analisando os resultados expostos na Tabela 4, verifica-se que as disciplinas consideradas não pregnantes para a formação, na avaliação dos alunos, não mereceriam ser retiradas do currículo, ainda que um importante número de respostas $(10,7 \%)$ indique que trocaria os professores das mesmas ou que solicitaria que se alterasse a maneira de trabalhar aqueles conteúdos, ampliando-os ou reduzindo-os. Este resultado também dá a clara dimensão de que o currículo por si mesmo ou as ementas das disciplinas só se concretizam quando de sua atualização no espaço da sala de aula. Daí decorrem, igualmente, sugestões tais como (i) alterações, tanto para a Licenciatura quanto para o curso de Formação de Psicólogo, (ii) rigor no cumprimento das ementas, (iii) maior preocupação com o ensino e (iv) aprofundamento dos conteúdos.

Quanto ao curso de Formação de Psicólogo, as alterações mais numerosas estão relacionadas à abertura do leque de ofertas de conteúdos eletivos ${ }^{7}$. O peso do curso na Psicanálise e na Psicologia Comportamental, fato restritivo de outras áreas, é também sempre apontado pelos alunos deste curso como muito importantes.

\section{Da "salada epistemológica" aos shibbolets ${ }^{8}$ do ensino de psicologia}

Como forma de aprimoramento da caminhada no sentido de melhor formar os professores de psicologia para que esta possa ocupar de forma viva e necessária os espaços da sala de aula do Ensino Fundamental e Médio, é preciso abstrair da reflexão acerca da ação docente alguns pontos referenciais que passem a constituir balizamento para este contexto de ensino e aprendizagem.

Experiências anteriores com alunos de Prática de Ensino de Psicologia permitiram constatar uma não apropriação do método didático específico para a área de ensino em questão, enquanto instrumento para a ação docente que contivesse num mesmo espaço o objeto do conhecimento e o trabalho dos sujeitos da ação educacional. A lacuna mais significativa residia na "salada epistemológica"que caracterizava o edifício teórico dos alunos e que servia de alicerce para os conteúdos específicos da Psicologia. Daí para a pouca condição de transformar dados em informações, informações em conhecimento e conhecimento em saber, não havia mais do que uma pequena distância. Dentre as alternativas para o enfrentamento deste problema, a reflexão conjunta acerca da ação de ensino e aprendizagem tem se mostrado a mais efetiva. Este tipo de ação consiste num shibbolet da Metodologia de Ensino de Psicologia.

Freud, em vários trabalhos e algumas correspondências, utiliza a palavra shibbolet para designar aquilo que em seu entendimento seriam os princípios norteadores da teoria psicanalítica. Esse termo Freud toma emprestado de seus estudos da 
Torá. Refere-se ao trecho do Antigo Testamento, livro dos Juízes (12,5-6), que relata uma luta fratricida entre duas tribos israelitas (Antunes, Heller \& Goldstein, 1998).

De início, desta feita, na qualidade de princípios, fundamentos, pedras angulares, pode-se partir tanto da reflexão conjunta acerca da ação docente quanto da parceria efetiva entre os participantes do processo de ensino-aprendizagem: alunos e professor. Cabe frisar que, em nenhum momento, ainda que trabalhando com adultos jovens, o professor deve abrir mão do papel de professor, daquele que, necessariamente, sabe-se à frente no momento de partida e, portanto, assume a direção do movimento de construção do conhecimento.

Dado o já referido diagnóstico inicial, que apontava a falta de coerência epistemológica do edifício de saberes dos alunos, aliado, como não poderia deixar de ser, à desintegração entre teoria e prática, é preciso buscar a criação de alternativas que focalizem a possibilidade de transcendência destas condições reais e funestas para o ensino, neste caso, o de psicologia.

Cabe aqui a observação do significado da definição de objetivos no trabalho docente que se pretenda transformador: é do estabelecimento do lugar no qual se pretende chegar que se faz possível desenhar os melhores caminhos ainda que a surpresa, o inusitado e, até mesmo, o susto não sejam passíveis de previsão e requeiram flexibilidade e capacidade de enfrentamento, já que a realidade não se prende em camisa de força. A organização prévia que então se sustenta em conhecimentos teóricos e em diagnóstico das condições de trabalho, constitui "régua e compasso"para todo o processo de ensino $\mathrm{e}$ aprendizagem.

Tal situação descreve a medida em que o conhecimento é adequado às necessidades. Pode-se saber muito, mas não o essencial. Pode-se saber pouco, mas o necessário. O que é então essencial na ação docente?

Ainda que não se deva considerar objetivos como moldes que devam conduzir a realidade a reboque, pode-se tomá-los como o leme a direcionar o pensamento que serve de pilar à ação docente.

$\mathrm{O}$ grupo, ao constituir-se como grupo, numa cumplicidade amorosa, tende a transformar o espaço há milênios reservado para a transmissão do conhecimento, num espaço de apropriação e construção de um saber - saber vivo, provisório. A interação das consciências, dos distintos esquemas referenciais, permite, desta maneira, que seja possível pouco a pouco colher o conhecimento sem deixar de acolher as dúvidas. O ambiente de trabalho desta natureza, via de regra, estimula o pensar, o estudo, a discussão e a crítica: todos desejados e apreciados pelos aprendizes em geral.

O relacionamento, assim como o conflito, pode ocorrer em distintos vetores: entre colegas, do professor para os alunos, dos alunos para o professor e de cada um com o pensamento, com o saber?.
"Conhecimento é coisa erótica, que engravida. Mas é preciso que o desejo faça o corpo se mover para o amor"(Alves, 1988).

Entende-se, aqui, que o professor que sabe, suporta mais ou menos bem tudo o que não sabe. Por esta razão, estuda, organiza, percebe e aceita as diferenças e se vê como um "amador"(no duplo sentido do termo) deste processo de ensino-aprendizagem, sendo também um eliciador do desejo que conduz para o amor.

Deste modo, é importante aqui caracterizar outro shibbolet deste processo: o papel do professor. Nem negligente, nem indulgente, nem meramente exigente; é o professor responsivo, aquele que, ao mesmo tempo, exige (de si e do outro) e reconhece que pode favorecer o desenvolvimento das consciências autônomas, dos sujeitos epistêmicos. Na medida em que o professor responsivo reconhece limites e esforços dos alunos, o mesmo tem condições de exigir esforços e desenvolvimento compatíveis com as condições próprias de cada um dos sujeitos do processo. Ao mesmo tempo em que age como alguém que se reconhece e se exige, isto é, firme, mas "sem perder a ternura", tem claro que as possibilidades de co-responsabilidade do ensino e da aprendizagem se fazem muito mais factíveis.

A natureza do exercício da função docente é, então, fator determinante (ainda que não o único e não suficiente por si só) do desenvolvimento de sujeitos autônomos, moral e cognitivamente. Daí que constitui, também, um shibbolet da metodologia de ensino de psicologia.

De fato,

ensinar psicologia é, em muitas aspectos, diferente do ensino de outros conteúdos, além de ser diferente de outras funções do próprio psicólogo. Em primeiro lugar, porque, como em outras ciências humanas em que a subjetividade de quem cria, compreende e ensina está tão intrinsecamente envolvida no processo, corre o risco de se ver prejudicada se o profissional em questão não tiver o suficiente discernimento de perceber com clareza o ethos de cada sociedade, além de necessitar uma clara consciência de si mesmo. Em segundo lugar, porque o psicólogo - como um cristal que visto de diferentes ângulos reflete diferentes cores sem, no entanto, deixar de ser cristal - é visto e vê a si mesmo em diferentes posições. Como terapeuta cabe-lhe interpretar; como supervisor, ajudar seu supervisionando a lidar com as situações transferenciais do seu trabalho e, como professor, auxiliar seu aluno a alcançar o saber necessário sem ter o direito de confundir uma situação com a outra, sob pena de produzir sérios prejuízos (Baibich, 1989, p. 23).

\section{Metodologia de Ensino de Psicologia: por uma didática clínica}

A abordagem clínica nas ciências humanas traz, do sentido etimológico do termo - observar diretamente, junto ao leito do paciente -, a conotação maior de estar "perto"ou "em face de"(como se traduz nos 
caracteres chineses), não na dimensão comum de curar ou cuidar, mas na preocupação de mudar, prevenir, melhorar uma dada situação e encontrar respostas a problemas. Com este sentido, reflete bem o significado da didática tratada neste estudo.

A fim de compreender os problemas da realidade, $o$ clínico em ciências humanas se coloca também "junto ao leito": ele trabalha principalmente em campo, e não em laboratório; ele não tenta somente compreender a doença (os problemas), mas compreender o doente (nesse caso, os grupos junto aos quais intervém). Quando ele comunica seus conhecimentos, não o faz somente para seus colegas profissionais, mas também para as pessoas e grupos que tem diante de si (Sévigny, 2001, pp. 15-16).

A dimensão fundamental da abordagem clínica é constituída pelos vínculos entre prática e teoria, sendo que, contrariamente à norma, a prioridade é dada à prática, à ação, à intervenção, pois o centro da análise é um problema a resolver ou, pelo menos, uma prática a explicar. As avaliações dos alunos formandos na Licenciatura em Psicologia de uma Instituição Federal de Ensino Superior, aliadas à experiência no ensino de Metodologia e de Prática de Ensino de Psicologia, indicam que tanto a atitude de "curvar-se ao leito"quanto a de tentar mudar para melhor uma situação real constituem molas propulsoras da ação docente. Assim, da mesma forma, a relação de parceria efetiva - tanto com os alunos, quanto com os professores da rede do Ensino Fundamental e Médio é o pré-requisito básico da produção, na ação, de conhecimento novo. A sistematização do conhecimento, sua disseminação com propósitos socializadores, também deve fazer parte dos objetivos primeiros do trabalho docente.

Este estudo, que se iniciou a partir de uma verificação empírica da ausência da Psicologia nos espaços da sala de aula ou, como já se disse, de sua presença gauche $e^{10}$, permitiu sugerir, mediante a análise de seus resultados, a existência de possibilidades concretas da Psicologia, pelo movimento de superação, transformar este "espaço esquerdo", sinistro, faltante, enviesado, num autêntico espaço de criação.

\section{REFERÊNCIAS}

Alves, R. (1988). Estórias de quem gosta de ensinar. São Paulo: Cortez.

Baibich, T. M. (1989). Comunicação didática nas diferentes concepções de ensino de Psicologia. Psicologia Argumento, vol. IX, $n^{\circ}$ 2, Curitiba: PUC/EDUCA.

Cunha, M. I. (1989). O bom professor e sua prática. Campinas: Papirus.

Faria, J. H. (2003). Economia política do poder: Os fundamentos da Teoria Crítica nos estudos das organizações. Curitiba: UFPR.

Freud, S. (1989). Contribución a la historia del movimiento psicoanalítico. Obras Completas, Tomo XXII. Argentina: Amorrortu.
Heller, A. G.; Antunes, C. A. \& Goldstein, J. (1998). O shibbolet da psicanálise. Revista Brasileira de Psicanálise, 32 (4), 685-696.

Sévigny, R. (2001). Abordagem clínica nas ciências humanas. Em J. N. G. Araújo \& T. C. Carreteiro (Orgs.), Cenários sociais e abordagem clínica. São Paulo: Escuta; Belo Horizonte: Fumec.

Wachowicz, L. A. (1989). O método dialético na didática. São Paulo: Papirus.

Recebido: 10.01.2003

Revisado: 02.06.2003

Aceito: 25.07.2003 


\begin{abstract}
Notas:
${ }^{1}$ Aqui entendida como presença à esquerda, pouco valorizada ou marginalizada.

${ }^{2}$ Realizada seis meses antes do preenchimento do questionário a ser analisado adiante.

${ }^{3}$ Ainda que se critique o Sistema Nacional de Avaliação de Cursos do Ministério da Educação - MEC, o assim chamado "Provão", a nota obtida por este curso em 2001 e em 2002 foi A.

${ }^{4}$ De qualquer modo, para a finalidade de se propor uma nova estrutura curricular, é conveniente que este quesito seja esclarecido. ${ }^{5}$ A atitude de autocrítica permanente, que se manifesta pelo reconhecimento do erro, pela postura de coordenação de diferentes pontos de vista e pela aceitação do "não-saber" é apontada nas avaliações qualitativas como fundamental para o ensino e a aprendizagem.

${ }^{6}$ Esta consideração revela as consequiências da cisão disciplinar de nossos cursos, o que leva os alunos a pouco considerarem a importância da cultura geral para qualquer formação profissional.

${ }^{7}$ Este fato já resolvido no currículo implantado em 2001, pelo menos em nível curricular.

${ }^{8}$ No país de Galaad viviam duas tribos israelitas, uma chefiada por Jefté e outra por Efraim. Essas duas tribos travaram uma guerra por território. Como possuíam uma origem comum tinham dificuldades de distinguir quem era o inimigo. Quando um judeu desconhecido descia das terras de Galaad buscando a margem oposta, os soldados de Jefté o prendiam. Seria aquele homem um agressor inimigo que abandonava Galaad ou um aliado fiel que retornava à sua aldeia? Para apurar a verdade fazia-se pronunciar a palavra shibbolet (espiga). Os partidários de Jefté pronunciavam shibbolet enquanto os partidários de Efraim diziam sibbolet. A primeira sílaba denunciava a diferença. E tudo ali, no mesmo instante, se decidia. Se o interrogado falseava na pronúncia, era logo degolado (Freud, 1914).

${ }^{9}$ Estabelece-se aqui uma distinção entre conhecimento e saber: entendo que o saber decorre do conhecimento assimilado pelo sujeito tanto com suas estruturas cognitivas quanto com as relativas ao emocional; assim, o sujeito sabedor, o sábio, tem condições de exercer aquilo que sabe, de forma autônoma e integrada. Seu discurso possui eco em sua forma de ser e de agir.

10 "Quando eu nasci veio um anjo torto e me disse: vai Carlos, ser gauche na vida" (Carlos Drummond de Andrade)
\end{abstract}

\title{
Sobre a autora
}

Tânia Maria Baibich: Psicóloga (UFRGS). Mestre em Educação (UFPR). Doutora em Psicologia Social (USP). Professora Adjunta III Setor de Educação UFPR. Pós-Doutoranda na Michigan University (2003). Visiting scholar na Universidade de Michigan. Endereço para correspondência: Rua São Pedro, 637/61 Cabral CEP 80035-020. Curitiba. Fone: (41) 252-2246. Email: tbaibich@terra.com.br. 